\title{
Erratum: What patients with bipolar disorder and major depressive disorder perceive as adverse life events precipitating a current major depressive episode
}

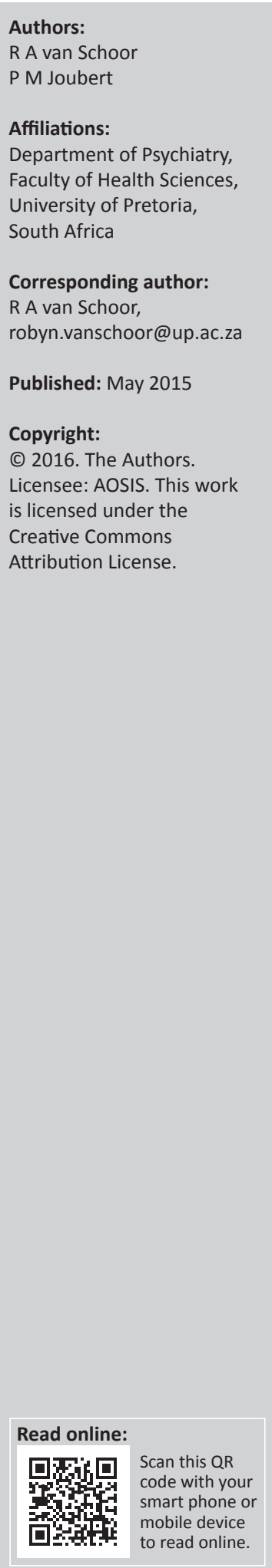

This article was erroneously published in 2015 under the DOI citation S Afr J Psychiatr 2015;22(2) instead of the correct S Afr J Psychiatr 2015;21(2). 